\title{
Blended Learning Methods in Specialization Graduate Courses Improve the Knowledge Gain Metric
}

\author{
Caíque Costa Dias ${ }^{1}$, Júlio César André ${ }^{2}$, Emerson Roberto dos Santos ${ }^{3}$, Heloísa Cristina Caldas ${ }^{4}$, Sérgio Luíz Aparecido \\ Brienze $^{5}$, Alba Regina de Abreu Lima ${ }^{6}$, Patrícia da Silva Fucuta ${ }^{7}$ \\ ${ }^{1}$ Undergraduate Student in Medicine, Medical School of Medicine of São José do Rio Preto - FAMERP, Brazil - \\ ORCID iD: https://orcid.org/0000-0003-0690-1769
}

${ }^{2}$ Center for the Study and Development of Health Education - CEDES, Medical School of Medicine of São José do Rio Preto - FAMERP, Brazil - ORCID iD: https://orcid.org/0000-0002-0549-4527

${ }^{3}$ Postgraduate Student in Posgraduation Program in Nursing, Medical School of Medicine of São José do Rio Preto FAMERP, Brazil - ORCID iD: https://orcid.org/0000-0002-9513-1083

${ }^{4}$ Laboratory of Immunology and Experimental Transplantation (LITEX), Medical School of Medicine of São José do Rio Preto - FAMERP, Brazil - ORCID iD: https://orcid.org/0000-0002-8303-3929

${ }^{5}$ Center for the Study and Development of Health Education - CEDES, Medical School of Medicine of São José do Rio Preto - FAMERP, Brazil - ORCID iD: https://orcid.org/0000-0003-4765-2340

${ }^{6}$ Center for the Study and Development of Health Education - CEDES, Medical School of Medicine of São José do Rio Preto - FAMERP, Brazil - ORCID iD: https://orcid.org/0000-0003-4332-4059

${ }^{7}$ Gastro-Hepatology Service at Hospital de Base of São José do Rio Preto - HB/FUNFARME, Brazil - ORCID iD: https://orcid.org/0000-0002-8342-4970

Correspondence: Júlio César André, Center for the Study and Development of Health Education - CEDES, Medical School of Medicine of São José do Rio Preto - FAMERP, Av. Brigadeiro Faria Lima, - 5416 - Vila São Pedro, Zip Code: 15090-000, São José do Rio Preto - SP Brazil.

Received: November 26, 2019

doi:10.11114/jets.v8i3.4673

\author{
Accepted: December 30, 2019 \\ Online Published: January 3, 2020
}

URL: https://doi.org/10.11114/jets.v8i3.4673

\begin{abstract}
Information and communication technologies (ICT) have been proven beneficial in teaching of health sciences courses. Combined e-learning strategies with face-to-face activities, among others, are defining characteristics of a new learning perspective called blended learning methods. The paucity of data to confirm the benefits of online forms of learning, in isolation or as a part of a blended learning method, indicates that more studies are still required to assess their influence on the teaching-learning process. This study measured knowledge gained using face-to-face (FtFA) and distance educational on virtual learning environments (DA-VLE) strategies in health sciences. For two consecutive years, FtFA and DA-VLE education strategies were used in a discipline of specialization graduate course, each discussing two topics. The knowledge gained using each strategy was assessed for each topic using a pre (PT) and post-test (PoT). The performance frequency (PF) of participants was categorized based on the number of correct answers in each assessed. The PF frequency increased between the PA and PoT in both strategies (FtFA and - DA-VLE), although higher scores were observed in DA-VLE strategies when compared to FtFA strategies. These data indicate that such strategies, within this context, are vital, and can bring benefits to the teaching-learning process in combination.
\end{abstract}

Keywords: information technologies, e-learning, lectures, self-instructing, assessment, health professionals

\section{Introduction}

The teaching of medicine as we know today is the result of a reform process initiated in 1910 from the observations made by Flexner about teaching at that time (Prober \& Health, 2012; Goudoris et al., 2013). However, more than 100 years after the publication of his report, this model has been proven fragile in the face of technological, scientific, and pedagogical advances achieved by the globalized world (Prober \& Health, 2012). Some medical schools have thus implemented alternative teaching methodologies to the Flexnerian model such as the introduction of information and communication technologies (ICT) in the preparation of online courses (Prober \& Health, 2012; Goudoris et al., 2013). 
Information and Communication technologies (ICT) have expanded access to information through computers, newspapers, magazines and radio (Garcia \& Carvalho Jr., 2015). In the teaching of medicine, ICT modify passive classroom teaching practices, engage students in the learning process and shorten time distances (Goudoris et al., 2013) mainly in areas with inadequate human and infrastructural resources like some African countries (Taye, 2014) as well as Brazil. ICT also assists in implementing online courses commonly referred to as e-learning, which use virtual learning environments (VLE) as teaching tools (Garcia \& Carvalho Jr., 2015).

The term e-learning is defined by Ellaway (2011) as "A vaguely defined amalgam of information and communication technologies used in education, generally - but not exclusively - mediated by the internet in some way." Teaching through this modality can be as effective as the traditional model (Reid et al., 2016; Cotič et al., 2016). Activities are conducted online and can be fulfilled synchronously or asynchronously by the participants (Garcia \& Carvalho Jr., 2015). Its main benefits are the flexibilization of the student's time, cost reduction, and functioning as a viable alternative to the permanent education process (Padalino \& Peres, 2007; Lahti et al., 2014; Rocha, 2015; Samulsky et al., 2016).

Also in the context of online education there are VLE, defined as software corresponding to face-to-face environments (classroom) (Garcia \& Carvalho Jr., 2015). They contain several activities (portfolios, tests, questionnaires) (Garcia \& Carvalho Jr., 2015) that satisfactorily assist in knowledge acquisition. The application of ICT in training processes in health has been shown to be effective at multiple education levels such as undergraduate, graduate (master's and doctorate; known in Brazil as stricto sensu) and specialization graduate courses (known in Brazil as latu sensu), continuing and extension education (Goudoris et al., 2013), and medical residency (Pinto et al., 2008) - included in the specialization category. Its use in undergraduate courses ranges from basic disciplines such as Anatomy (Acosta et al., 2018; Khalil et al., 2018), Histology (Santa-Rosa \& Struchiner, 2011; Vasconcelos \& Vasconcelos, 2013), and clinic (Gulat et al., 2019), to technical skills such as physical examination (Tenison \& Touger-Decker, 2018), and even in the learning of professional ethics (Aguilar-Rodriguez et al., 2019). Other successful examples are also found in the field of continuing education (Oliveira et al., 2013), namely the use of the Moodle platform for working groups such as the Professor Development Program for Educators of the Health Professions of Instituto Regional FAIMER ${ }^{\circledR}$ Brasil $_{\text {(Garcia }}$ \& Carvalho Jr., 2012).

The use of e-learning has crossed the boundaries of the most traditional teaching methodologies - lectures - and permeated the most active methodologies such as problem-based learning (PBL) (Chan et al., 2016; Shimizu et al., 2019), appearing in PBL as the strategy with the best academic performance (Ding \& Zhang, 2018), and interactive narratives (Scamell \& Hanley, 2017).

However, the existence of limitations must be considered such as in the case of the training of health professionals in clinical interventions for the results of knowledge and clinical behavior, and the clinical skills of health students, where the low quality of evidence does not allow firm conclusions on the relative efficacy of these training methods (Cook, 2009; Lahti et al., 2014; Mirmoghtadaie et al., 2016; Richmond et al., 2017). Despite the general interest on e-learning, critical reviews have cast suspicion on its effectiveness (Lahti et al., 2014; Mirmoghtadaie et al., 2016; Kyaw et al., 2019).

Although the use of ICT has proved beneficial in teaching health sciences through VLE and other methodologies (Santa-Rosa \& Struchiner, 2011; Garcia \& Carvalho Jr., 2012; Pereira et al., 2012; Rowe et al., 2012; Silva et al.; Vasconcelos \& Vasconcelos, 2013; Vovides et al., 2014; Richmond et al., 2017), some unfavorable factors observed during its implementation ought to be highlighted. They are: institutional support, faculty involvement, student involvement, technical knowledge, support and infrastructure systems in which health sciences institutions ought to invest in while equipping human resources to utilize the technological infrastructure (Rowe, 2012; Han et al., 2014; Cotič et al., 2016). Other aspects are related to the student perception that online courses should only be complementary and not substitutes for traditional classes (Vasconcelos \& Vasconcelos, 2013). Account must also be taken of the individual learning objectives (Nilsson et al., 2019) which are important in self-regulated learning (SRL) which emphasizes the autonomy and control by the individuals who direct, monitor, and regulate learning to achieve their goals and expertise. It has become increasingly a common theme in medical education over the last decade and plays a vital role not only during university years, but also when the students qualify and start practicing as doctors in the real world (Siddaiah-Subramanya et al., 2017).

Combined and asynchronous e-learning strategies (Baig et al., 2019), use of video recordings (Donkin et al., 2019), face-to-face activities among others, characterize blended learning, which allows new instructional methods and student-centered education to be used (de Jong, 2014), a developing strategy in terms of implementation.

There is limited information in the literature on the effects of e-learning strategies on the teaching-learning process. More studies are therefore needed to evaluate the effects of e-learning strategies - in isolation or as part of a blended learning program - on the teaching-learning process (Renno Junqueira et al., 2012; Vasconcelos \& Vasconcelos, 2013; Harder, 2013). This study seeks to evaluate the effects of online education in a face-to-face specialization graduate course. 


\section{Methods}

\subsection{Study Classification and Participants}

This is a quasi-experimental, descriptive, cross-sectional study conducted with students from the Clinical Analyses Specialization Graduate Course of Faculdade de Medicina de São José do Rio Preto (FAMERP), in 2016 and 2017, in the discipline Cellular Mechanisms of Reaction to Injuries - CMRI, with 50 students in total (2016 class: $\mathrm{n}=32$; and 2017 class: $n=18$ ). This study was approved by the Research Ethics Committee, CAAE: 7631217.0.0000.5415.

\subsection{Educational Strategies Used}

Educational strategies in both classes were divided into 2 groups that were respectively called Face-to-Face Activities (FtFA) and Distance Activities in Virtual Learning Enviromente (DA-VLE). Two distinct topics were addressed in each of the strategies: FtFA: a) Routine Procedures for Biopsies and Surgical Parts (RPBSP) and b) Cell Adaptation to Injuries (CAI); and DA-VLE: a) Inflammation (I) and Hemodynamic Disorders (HD).

For the face-to-face (FtFA) strategy, the class topic was formally presented (formal class) by the professor using PowerPoint slides as an auxiliary device to the professor's speech. This class lasted 3 hours with a 20-minute interval for rest (Total duration: 3 hours and 20 minutes).

For the DA-VLE strategy, students had access to the PowerPoint slides on the subject (Study Material - SM) and to a study guide on a virtual platform $\left(\right.$ WIX $^{\odot}$ ) availed to them for a time interval equal to that of the FtFA strategy.

\subsection{Assessment Procedures}

The students undertook a knowledge assessment before (pre-test - PT) and after (post-test - PoT) exposure to each educational strategy to ascertain their background knowledge and their gained knowledge on the subject, respectively. The assessments consisted of 30 multiple choice questions, elaborated by a teacher other than the one who taught the topic. Additionally, the questions were the same in the PT and PoT of each topic but the students were unaware of this. The tests were performed immediately before and after the teacher's presentation and in a similar fashion for the virtual environment for comparability. The performance frequency (PF) was categorized into LOW ( $<10$ correct answers), MEDIUM (10-20 correct answers) and HIGH (>20 correct answers).

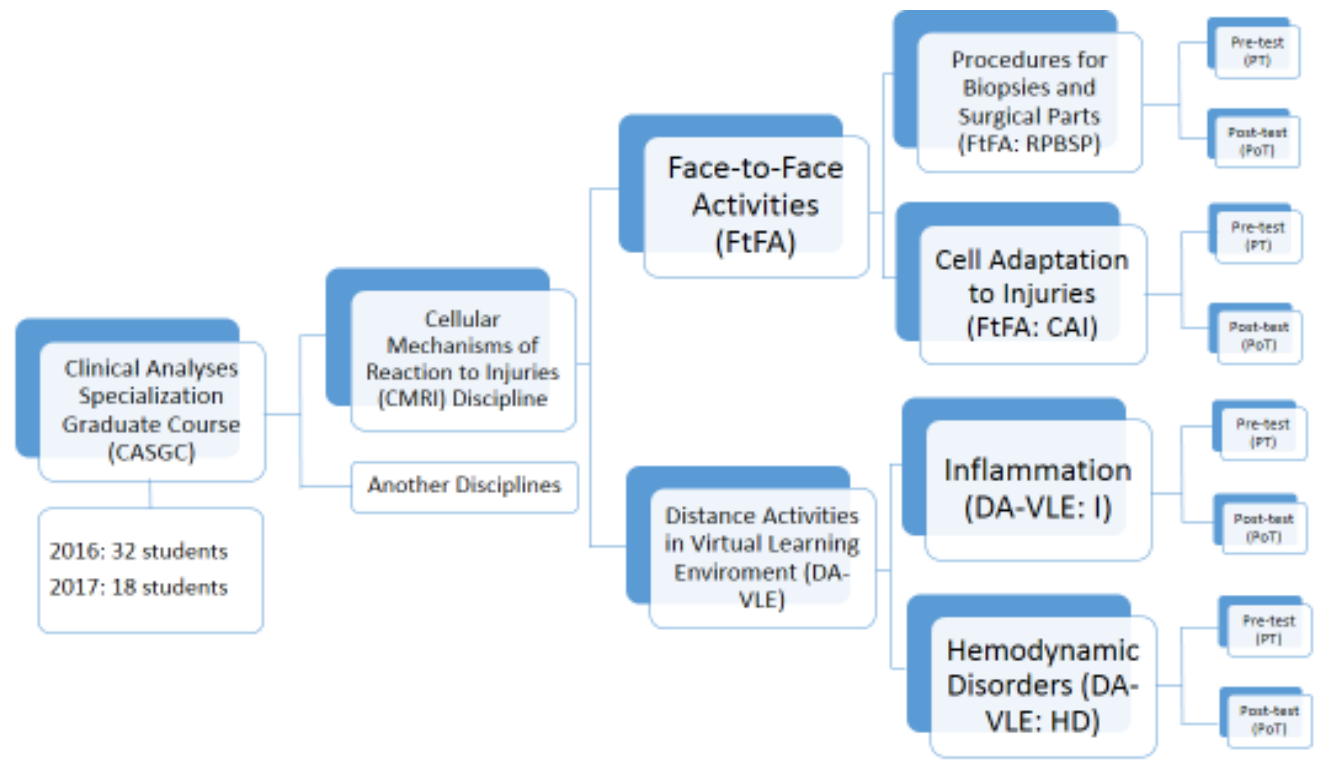

Figure 1. Illustrative scheme of educational strategies used and assessment procedures

\subsection{Data Analysis}

Data was presented as absolute numbers and percentages. The Chi Square test or Fisher's exact test were used to compare proportions. All tests were two-tailed and significance was considered when $\mathrm{P}<0.05$. Statistical analysis was performed using the StatsDirect software version 3.0.171. 


\section{Results}

A total of 50 students were included in the study, all from the Specialization Graduate Course in Clinical Analyses of Faculdade de Medicina de São José do Rio Preto (FAMERP). The same students in each academic year (2016 and 2017) undertook assessments in the 4 different topics, however, the total number of assessments available for analyses from the 50 students was 182 (some of the 50 students did not complete all 4 topic assessments).

The pre-test of the students' knowledge in the FtFA and DA-VLE performed by PF in the studied topics showed that 78 students $(42.8 \%)$ had low scores, $101(55.5 \%)$ had medium scores, and only $3(1.6 \%)$ had high scores. (Table 1). When comparing the two groups - FtFA and DA-VLE -, the analysis showed a similarity between groups with most scores in the low and medium ranges (Table 1).

After exposure to the educational strategies, the students showed higher frequency of scores in the moderate and high ranges $(30.7 \%$ and $67.6 \%$, respectively). Comparing the FtFA and DA-VLE groups, after the educational strategies students in the DA-VLE group showed a high level of knowledge when compared with the FtFA group (FtFA high scores $=42 \%$ vs. DA-VLE high scores $=89 \%$; $p<0.0001)$ (Table 1).

Table 1. Performance frequency (PF) of students in pre (PT) and post-test (PoT) in face-to-face (FtFA) and distance activities (DA-VLE) in the topics assessments in the discipline, 2016 and 2017

\begin{tabular}{|c|c|c|c|c|}
\hline $\begin{array}{l}\text { PF } \\
\text { PT }\end{array}$ & All $(n=182)$ & FtFA $(n=83)$ & DA-VLE $(n=99)$ & p-value \\
\hline $\operatorname{Low}[n(\%)]$ & $78(42.8 \%)$ & $38(45.7 \%)$ & $40(40.4 \%)$ & 0.54 \\
\hline Moderate [n(\%)] & $101(55.5 \%)$ & $43(52 \%)$ & $58(58.6 \%)$ & 0.89 \\
\hline $\operatorname{High}[\mathrm{n}(\%)]$ & $3(1.6 \%)$ & $2(2.4 \%)$ & $1(1 \%)$ & 0.60 \\
\hline $\begin{array}{c}\text { PF } \\
\text { PoT }\end{array}$ & All $(n=182)$ & FtFA $(n=83)$ & DA-VLE $(n=99)$ & p-value \\
\hline $\operatorname{Low}[n(\%)]$ & $3(1.6 \%)$ & $3(3.6 \%)$ & 0 & 0.1 \\
\hline Moderate [n(\%)] & $56(30.7 \%)$ & $45(52.2 \%)$ & $11(11.1 \%)$ & $<0.0001$ \\
\hline High $[\mathrm{n}(\%)]$ & $123(67.6 \%)$ & $35(42 \%)$ & $88(89 \%)$ & $<0.0001$ \\
\hline
\end{tabular}

Observing the PF and comparing the PT and PoT results of FtFA students, the analysis shows that in both evaluated topics (CAI and RPBSP) the participants' performance was better on PoT (Table 2), and on the topics assessments in DA-VLE (I and HD) students also presented better performance on PoT (Table 3).

Table 2. Performance frequency (PF) of students in face-to-face activities (FtFA) in the topics assessment

\begin{tabular}{|c|c|c|c|c|}
\hline FtFA $(n=99)$ & PF & PT & PoT & p-value \\
\hline \multirow{3}{*}{ I $(\mathbf{n}=\mathbf{5 0})$} & $\operatorname{Low}[n(\%)]$ & $14(28 \%)$ & $\mathbf{0}$ & $<0.0001$ \\
\hline & Moderate $[n(\%)]$ & $35(70 \%)$ & $6(12 \%)$ & $<0.0001$ \\
\hline & $\operatorname{High}[\mathrm{n}(\%)]$ & $1(2 \%)$ & $44(88 \%)$ & $<0.0001$ \\
\hline \multirow{3}{*}{ HD $(n=49)$} & $\operatorname{Low}[n(\%)]$ & $26(53 \%)$ & $\mathbf{0}$ & $<0.0001$ \\
\hline & Moderate [n(\%)] & $23(47 \%)$ & $5(10.2 \%)$ & $<0.0001$ \\
\hline & High $[n(\%)]$ & $\mathbf{0}$ & $44(89.8 \%)$ & $<0.0001$ \\
\hline
\end{tabular}


Table 3. Performance frequency (PF) of students in distance activities (DA-VLE) in the topics assessment

\begin{tabular}{|c|c|c|c|c|}
\hline DA-VLE $(n=83)$ & $\mathbf{P F}$ & PT & PoT & p-value \\
\hline \multirow{3}{*}{ CAI $(n=46)$} & Low $[n(\%)]$ & $15(32.6 \%)$ & $3(6.5 \%)$ & 0.003 \\
\hline & Moderate $[\mathrm{n}(\%)]$ & $29(63 \%)$ & $17(37 \%)$ & 0.02 \\
\hline & High $[n(\%)]$ & $2(4.4 \%)$ & $26(56.5 \%)$ & $<0.0001$ \\
\hline \multirow{3}{*}{$\operatorname{RPBSP}(\mathbf{n}=37)$} & $\operatorname{Low}[\mathrm{n}(\%)]$ & $23(62.2 \%)$ & $\mathbf{0}$ & $<0.0001$ \\
\hline & Moderate [n(\%)] & 14(37.8\%) & $28(75.7 \%)$ & 0.002 \\
\hline & High $[n(\%)]$ & $\mathbf{0}$ & $9(24.3 \%)$ & 0.002 \\
\hline
\end{tabular}

Thus, although the PF between PT and PoT increased for both strategies (FtFA and DA-VLE), the increase was higher in the DA-VLE strategy when compared with FtFA (Tables 2 and 3).

\section{Discussion}

Given the advances presented by information and communication technologies in all sectors of society, combined strategies for teaching-learning can be used to respond to the needs of constant reform in education for health sciences. Such rapid advances in ICT have caused increasingly challenging and complex changes in pedagogical and andragogical strategies.

However, the transition from traditional learning to online learning is not free of challenges. Increasing time restrictions and demands are continually imposed on students and educators alike, driving educational institutions to find new ways to provide a more personalized and self-directed learning experience (O'Doherty et al., 2018).

Combined e-learning experiences with face-to-face education has increasingly attracted attention from educators, and has become an integral part of medical education strategies (Ruiz et al., 2006), especially with students widely embracing technology in their daily lives (de Leeuw et al., 2019).

This study compared face-to-face and distance education strategies and assessments content learning before and after the exposition of the proposed themes using performance frequency. The students' PF was evaluated in the FtFA and DA-VLE groups at both moments of the study: pre-test (PT) of their knowledge and after exposure to educational strategies (post-test - PoT). Our results show both groups had a knowledge gain in the PoT moment, considering that such PF increase is higher in the DA-VLE strategy when compared with FtFA one. Distance education was thus more responsive in our study. Chumley-Jones et al. (2002) show evidence about the benefits of e-learning, which in some cases is equivalent to or better than traditional learning, allowing greater acquisition of knowledge by the student. Moreover, the literature suggests higher rates of student satisfaction with e-learning, mainly due to its convenience, flexibility, and interactivity (Ruiz et al., 2006), allowing the user to control the content, learning sequence, pace and time chosen to study (Nilsson et al., 2019).

Sadeghi et al. (2014) reiterate that blended methods significantly increase the knowledge of students. Because student satisfaction and the cost-benefit ratio for the blended method are higher than in the formal method, we highly recommends that teachers use e-learning teaching methods as a complementary approach to theoretical teaching methods. This is corroborated by the results presented in our study since knowledge gain occurred in both educational strategies.

Health students need to assimilate new information during their studies, especially with the need for evidence-based practices; they also need to develop lifelong learning skills while keeping their knowledge updated and motivation for studies (Kim et al., 2016). Teaching strategies have thus evolved with changes in the conception of learning methods of traditional face-to-face teaching, seeking innovative methods that reorient the training of professionals towards the problematization of reality and integral health care (Lampert, 2008; Manoel, 2012).

E-learning can occur in several modalities, that is, in face-to-face, blended, and virtual environments (Kim et al., 2016). Our study used a virtual learning platform (WIX ${ }^{\circledR}$ ), i.e., we used technological resources to support the discipline, and such virtual scenario stimulated learning significantly. In a scenario where digital globalization and content problematization become vital for students to acquire knowledge in learning processes, information and communication technologies in virtual environments enable student emancipation in the face of the development of individual skills; we thus enter the field of self-regulated learning, which is described as being directed by one monitoring their own learning needs and using the instruments necessary to support the learning process (Lycke et al., 2006; Sandars \& Cleary, 2011; Vermut \& Donche, 2017). Self-regulated learning theories shed light on incentives and approaches of students regarding 
flexible learning tools (Winters et al., 2008; Devolder \& van Braak, 2012).

All innovation can be exciting as a novelty, and the innovations brought about by e-learning in the distance activities of our study used as a complementary resource based on a VLE contributed to the learning of students based on self-regulated learning principles, in which students make their decisions based on several factors, including individual strategies to regulate their learning. One of the comprehensive aspects of this resource is its relationship with individual learning goals (Nilsson et al., 2019).

The main limitations of this study are its limited sample size, the specific studied topics and the identical pre and post-test questions. Nevertheless, we believe the results of this study contribute to reflections on the importance of distance education models and the integration of technologies and virtual learning environments to face-to-face health education. This study also contributes information on the effectiveness of pre- and post-tests as an assessment strategy for knowledge gain. We recommend that future studies be conducted with different sets of pre and post-test questions testing the same concepts in knowledge acquisition to enhance validity. We must note that although the knowledge gain measure is restricted to the cognitive component, this component is necessary for the development of competences, a concept that since 1956 took on the world from Benjamin Bloom, whose taxonomy of educational objectives includes the cognitive domain (knowledge), psychomotor domain (skills), and affective domain (attitudes) (Bloom et al., 1956).

Although the physical distance between professors and students and communication using media are a challenge for educational institutions due to requiring investments on technologies and changes in the culture of professors and students - who are accustomed to the face-to-face learning model (Mugnol, 2009), and that much still needs to be elucidated about self-regulated learning, the conclusions of this investigation can serve as the basis for further studies aimed at improving the teaching-learning process in the different teaching modalities, and paraphrasing Siddaiah-Subramanya et al.: "Self-regulated learning is vital throughout life in the current era. Learning how to learn is critical. It is under the influence of intuitions and beliefs, which can harm the process or increase effectiveness. Becoming a sophisticated learner requires basic understanding of the learning process, identifying and interpreting errors and avoiding the mentality that one's learning capacity cannot change; encouraging the mind to think freely and appreciate the incredible human capacity" (Siddaiah-Subramanya et al., 2017).

\section{Acknowledgements}

We thank PhD. Margarete Teresa Gottardo de Almeida, coordinator of the Specialization Graduate Course in Clinical Analyses of Faculdade de Medicina de São José do Rio Preto (FAMERP) for allowing us to develop this research in her course.

\section{References}

Acosta, M. L., Sisley, A., Ross, J., Brailsford, I., Bhargava, A., Jacobs, R., \& Anstice, N. (2018). Student acceptance of e-learning methods in the laboratory class in Optometry. PLoS One, 13(12). https://doi.org/10.1371/journal.pone.0209004

Aguilar-Rodríguez, M., Marques-Sule, E., Serra-Añó, P., Espí-López, G. V., Dueñas-Moscardó, L., \& Pérez-Alenda, S. (2019). A blended-learning programme regarding professional ethics in physiotherapy students. Nursing Ethics, 26(5), 1410-1423. https://doi.org/10.1177/0969733017748479

Baig, Q. A., Abbas Zaidi, S. J., \& Alam, B. F. (2019). Perceptions of dental faculty and students of E-learning and its application in a public sector Dental College in Karachi, Pakistan. Journal of the Pakistan Medical Association, 69(9), 1320-1325. https://jpma.org.pk/article-details/9317?article_id=9317

Bloom, B., Engelhart, M., Furst, E., Hill, W., \& Krathwohl, D. (1956). Taxonomy of educational objectives. Handbook I: Cognitive Domain. (2nd ed.). New York, NY: Addison-Wesley Longman Ltd.

Chan, A. W., Chair, S. Y., Sit, J. W., Wong, E. M., Lee, D. T., \& Fung, O. W. (2016). Case-Based Web Learning Versus Face-to-Face Learning: A Mixed-Method Study on University Nursing Students. Journal of Nursing Research, 24(1), 31-40. https://doi.org/10.1097/jnr.0000000000000104

Chumley-Jones, H. S., Dobbie, A., \& Alford, C. L. (2002). Web-based learning: sound educational method or hype? A review of the evaluation literature. Academic Medicine, 77(10 Suppl), S86-93. https://doi.org/10.1097/00001888-200210001-00028

Cook, D. A. (2009). The failure of e-learning research to inform educational practice, and what we can do about it. Medical Teacher, 31(2), 158-162. https://doi.org/10.1080/01421590802691393

Cotič, Ž., Rees, R., Wark, P. A., \& Car, J. (2016). Factors influencing the implementation, adoption, use, sustainability and scalability of eLearning for family medicine specialty training: a systematic review protocol. Systematic Reviews, 5(1), 179. https://doi.org/10.1186/s13643-016-0352-z 
de Jong, N., Savin-Baden, M., Cunningham, A. M., \& Verstegen, D. M. (2014). Blended learning in health education: three case studies. Perspectives on Medical Education, 3(4), 278-288. https://doi.org/10.1007/s40037-014-0108-1

de Leeuw, R., de Soet, A., van der Horst, S., Walsh, K., Westerman, M., \& Scheele, F. (2019). How we evaluate postgraduate medical e-learning: systematic review. JMIR Medical Education, 5(1), e13128. https://doi.org/10.2196/13128

Devolder, A., \& van Braak, J. (2012). Supporting self-regulated learning in computer-based learning environments: systematic review of effects of scaffolding in the domain of science education. Journal of Computer Assisted Learning, 28(6), 557-573. https://doi.org/10.1111/j.1365-2729.2011.00476.x

Ding, Y., \& Zhang, P. (2018). Practice and effectiveness of web-based problem-based learning approach in a large class-size system: A comparative study. Nurse Education in Practice, 31, 161-164. https://doi.org/10.1016/j.nepr.2018.06.009

Donkin, R., Askew, E., \& Stevenson, H. (2019). Video feedback and e-Learning enhances laboratory skills and engagement in medical laboratory science students. BMC Medical Education, 19, 310. https://doi.org/10.1186/s12909-019-1745-1

Ellaway, R. (2011). E-learning: is the revolution over? Medical Teacher, 33(4), 297-302. https://doi.org/10.3109/0142159X.2011.550968

Garcia, V. L., \& Carvalho Jr, P. M. (2012). Human health resource training: information and communication technologies as a teaching resource in the Faimer Brazil Program. Revista do Hospital Universitário Pedro Ernesto, 11(Supl 1). Retrieved from http://revista.hupe.uerj.br/detalhe_artigo.asp?id=311

Garcia, V. L., \& Carvalho Jr., P. (2015). Distance Learning - concepts and reflections. Medicina (Ribeirao Preto. Online), 48(3), 209-213. https://doi.org/10.11606/issn.2176-7262.v48i3p209-213

Goudouris, E. S., Giannella, T. R., \& Struchiner, M. (2013). Information and Communication Technology and Blended Learning in Medical Education. Revista Brasileira de Educação Médica, 37(3), 396-407. https://doi.org/10.1590/S0100-55022013000300012

Han, H., Nelson, E., \& Wetter, N. (2014). Medical students' online learning technology needs. Clinical Teacher, 11(1), 15-19. https://doi.org/10.1111/tct.12092

Harder, B. (2013). Are MOOCs the future of medical education? BMJ, 346, f2666. https://doi.org/10.1136/bmj.f2666

Khalil, M. K., Abdel-Meguid, E. M., \& Elkhider, I. A. (2018). Teaching of anatomical sciences: A blended learning approach. Clinical Anatomy, 31(3), 323-329. https://doi.org/10.1002/ca.23052

Kim, K. J., Kang, Y., \& Kim, G. (2016). The current status and future directions of e-Learning in medical education in Korea. Medical Teacher, 38(8), 860. https://doi.org/10.1080/0142159X.2016.1204434

Kyaw, B. M., Posadzki, P., Paddock, S., Carro, J., Campbell, J., \& Car, L. T. (2019). Effectiveness of digital education on communication skills among medical students: systematic review and meta-analysis by the digital health education collaboration. Journal of Medical Internet Research, 21(8). https://doi.org/10.2196/12967

Lahti, M., Hatonen, H., \& Valimaki, M. (2014). Impact of e-learning on nurses' and student nurses knowledge, skills, and satisfaction: a systematic review and meta-analysis. International Journal of Nursing Studies, 51(1), 136-149. https://doi.org/10.1016/j.ijnurstu.2012.12.017

Lampert, J. B. (2008). Two centuries of Brazilian Medical Schools and the assessment medical education in the present and future view. Gazeta Medica da Bahia, 78(Supl 1), 31-37. Retrieved from http://www.gmbahia.ufba.br/adm/arquivos/artigo05_2008sup1\%5B1\%5D.pdf

Lycke, K., Grøttum, P., \& Strømsø, H. I. (2006). Student learning strategies, mental models and learning outcomes in problem-based and traditional curricula in medicine. Medical Teacher, 28(8), 717-722. https://doi.org/10.1080/01421590601105645

Manoel, C. M. (2012). The multiprofessional and interdisciplinary experience of university-services-community interaction: the look and work of the tutor teacher (Unpublished master's thesis). Universidade Estadual Paulista, Botucatu, São Paulo. Retrieved from https://repositorio.unesp.br/bitstream/handle/11449/106071/manoel_cm_dr_botfm.pdf?sequence=1\&isAllowed=y

Mirmoghtadaie, Z., Ahmady, S., Yazdani, S., Mojtahedzadeh, R., \& Afshar, L. (2016). Professional practice of medical training in the e-learning system: the conceptual model based on a critical review. Journal of Medical Education, 15(4), 214-20. http://journals.sbmu.ac.ir/jme/article/view/13480 
Mugnol, M. (2009). Distance education in Brazil: concepts and foundations. Revista Diálogo Educacional, 9(27), 335-349. https://doi.org/10.7213/rde.v9i27.3589

Nilsson, M., Fors, U., Östergren, J., Bolinder, G., \& Edelbring, S. (2019). Why medical students choose to use or not to use a web-based electrocardiogram learning resource: mixed methods study. JMIR - Journal of Medical Internet Research, 5(2), e12791. https://doi.org/10.2196/12791

O'Doherty, D., Dromey, M., Lougheed, J., Hannigan, A., Last, J., \& McGrath, D. (2018). Barriers and solutions to online learning in medical education-an integrative review. BMC Medical Education, 18(1), 130. https://doi.org/10.1186/s12909-018-1240-0

Oliveira, A. E. F., Ferreira, E. B., Sousa, R. B., Castro Junior, E. F., \& Lopes e Maia, M. F. (2013). Distance learning and continuing education: searching for progress in health. Revista Brasileira de Educação Médica, 37(4), 578-583. https://doi.org/10.1590/S0100-55022013000400014

Padalino, Y., \& Peres, H. H. C. (2007). E-Learning: a comparative study for knowledge apprehension among nurses. Revista Latino-Americana de Enfermagem, 15(3), 397-403. https://doi.org/10.1590/S0104-11692007000300006

Pereira, B. M. T., Calderan, T. R. A., Silva, M. T. N., Silva, A. C., Mattos Jr, A. C., \& Fraga, G. P. (2012). Initial experience at a university teaching hospital from using telemedicine to promote education through video conferencing. Sao Paulo Medical Journal, 130(1), 32-36. https://doi.org/10.1590/S1516-31802012000100006

Pinto, A., Selvaggi, S., Sicignano, G., Vollono, E., Iervolino, L., Amato, F., ... Grassi, R. (2008). E-learning tools for education: regulatory aspects, current applications in radiology and future prospects. Radiologia Medica, 113(1), 144-157. https://doi.org/10.1007/s11547-008-0227-z

Prober, C. J., \& Health, C. (2012). Lecture halls without lectures--a proposal for medical education. New England Journal of Medicine, 366(18), 1657-1659. https://doi.org/10.1056/NEJMp1202451

Reid, H. J., Thomson, C., \& Mcglade, K. J. (2016). Content and discontent: a qualitative exploration of obstacles to elearning engagement in medical students. BMC Medical Education, 16, 188. https://doi.org/10.1186/s12909-016-0710-5

Renno Junqueira, C., Tavares da Silva, P. M., Renno Junqueira, S., \& Ramos, D. L. P. (2012). Bioethics teaching: evaluation of students through internet discussion forums. Acta Bioethica, 18(1), 93-100. https://doi.org/10.4067/S1726-569X2012000100008

Richmond, H., Copsey, B., Hall, A. M., Davies, D., \& Lamb, S. E. (2017). A systematic review and meta-analysis of online versus alternative methods for training licensed health care professionals to deliver clinical interventions. BMC Medical Education, 17, 227. https://doi.org/10.1186/s12909-017-1047-4

Rocha, J. S. Y. (2015). Use of information and communication technologies in healtheducation. Problems and development. Medicina (Ribeirão Preto. Online), 48(3), 214-223. https://doi.org/10.11606/issn.2176-7262.v48i3p214-223

Rowe, M. (2012). The use of a wiki to facilitate collaborative learning in a South African physiotherapy department. South African Journal of Physiotherapy, 68(2), 11-16. https://doi.org/10.4102/sajp.v68i2.10

Rowe, M., Frantz, J., \& Bozalek, V. (2012). The role of blended learning in the clinical education of healthcare students: a systematic review. Medical Teacher, 34(4), e216-e221. https://doi.org/10.3109/0142159X.2012.642831

Ruiz, J. G., Mintzer, M. J., Leipzig, R. M. (2006). The impact of E-learning in medical education. Academic Medicine, 81(3):207-212. https://doi.org/10.1097/00001888-200603000-00002

Sadeghi, R., Sedaghat, M. M., \& Sha Ahmadi, F. (2014). Comparison of the effect of lecture and blended teaching methods on students' learning and satisfaction. Journal of Advances in Medical Education \& Professionalism, 2(4), 146-150. Retrieved from https://www.ncbi.nlm.nih.gov/pmc/articles/PMC4235559/pdf/jamp-2-146.pdf

Samulski, T. D., La, T., \& Wu, R. I. (2016). Adaptive eLearning modules for cytopathology education: A review and approach. Diagnostic Cytopathology, 44(11), 944-951. https://doi.org/10.1002/dc.23558

Sandars, J., \& Cleary, T. J. (2011). Self-regulation theory: applications to medical education: AMEE Guide No 58. Medical Teacher, 33(11), 875-886. https://doi.org/10.3109/0142159X.2011.595434

Santa-Rosa, J. G., \& Struchiner, M. (2011). Educational technology in the teaching of histology: research and development in a virtual teaching and learning environment. Revista Brasileira de Educação Médica, 35(2), 289-298. https://doi.org/10.1590/S0100-55022011000200020

Scamell, M., \& Hanley, T. (2017). Innovation in preregistration midwifery education: Web based interactive storytelling 
learning. Midwifery, 50, 93-98. https://doi.org/10.1016/j.midw.2017.03.016

Shimizu, I., Nakazawa, H., Sato, Y., Wolfhagen, I. H. A. P., \& Könings, K. D. (2019). Does blended problem-based learning make Asian medical students active learners?: a prospective comparative study. BMC Medical Education, 19, 147. https://doi.org/10.1186/s12909-019-1575-1

Siddaiah-Subramanya, M., Nyandowe, M., \& Zubair, O. (2017). Self-regulated learning: why is it important compared to traditional learning in medical education? Advances in Medical Education and Practice, 8, 243-246. https://doi.org/10.2147/AMEP.S131780

Silva, C. C. B. M., Toledo, S. L. P., Silveira, P. S. P., \& Carvalho, C. R. F. (2012). Evaluation of a multimedia online tool for teaching bronchial hygiene to physical therapy students. Brazilian Journal of Physical Therapy, 16(1), 68-73. https://doi.org/10.1590/S1413-35552012000100012

Taye, B. (2014). Online discussion for block teaching in postgraduate health professionals' curriculum: the Ethiopian experience. BMC Medical Education, 14(1), 29. https://doi.org/10.1186/1472-6920-14-29

Tenison, E., \& Touger-Decker, R. (2018). Impact of e-Learning or blended learning versus face-to-face learning in regard to physical examination skills, knowledge, and attitudes among health professions students. Topics in Clinical Nutrition, 33(3), 259-270. https://doi.org/10.1097/TIN.0000000000000149

Vasconcelos, D. F. P., \& Vasconcelos, A. C. C. G. (2013). Development of a virtual learning environment in histology for health students. Revista Brasileira de Educação Médica, 37(1), 132-137.

https://doi.org/10.1590/S0100-55022013000100019

Vermunt, J., \& Donche, V. (2017). A learning patterns perspective on student learning in higher education: state of the art and moving forward. Educational Psychology Review, 29(2), 269-299. https://doi.org/10.1007/s10648-017-9414-6

Vovides, Y., Chale, S. B., Gadhula, R., Kebaetse, M. B., Nigussie, N. A., Suleman, F., Nkomazana, O. (2014). A systems approach to implementation of eLearning in medical education: five MEPI schools' journeys. Academic Medicine, 89(8), S102-S106. https://doi.org/10.1097/ACM.0000000000000347

Winters, F., Greene, J., \& Costich, C. (2008). Self-regulation of learning within computer-based learning environments: a critical analysis. Educational Psychology Review, 20(4), 429-444. https://doi.org/10.1007/s10648-008-9080-9

\section{Copyrights}

Copyright for this article is retained by the author(s), with first publication rights granted to the journal.

This is an open-access article distributed under the terms and conditions of the Creative Commons Attribution license which permits unrestricted use, distribution, and reproduction in any medium, provided the original work is properly cited. 